\title{
Periodismo y verdad
}

\author{
Sonia Luz Carrillo Mauriz \\ Departamento Académico de Comunicación Social
}

$\mathbf{E}$

n el Perú de 2002, una rápida mirada a los titulares de cierta prensa perua-

na o la audición de éstos al inicio de un informativo radial o televisivo nos dejan la sensación de caos institucional, problemas sin solución a la vista, fallas éticas de todo calibre, extendida e imbatible corruptela. No se puede confiar en nadie. Todos estamos marcados por la malignidad. El clima es de confrontación y de invitación al suicidio. El mal campea absoluto. La buena noticia no es noticia, opinan los más reputados manejadores de medios. El espectáculo tiene visos sadomasoquistas. Miente, miente que algo queda, noticias que un día alborotan el ambjente sin que sus creadores se hayan tomado la molestia de consultar diversas fuentes y mucho menos haberse planteado la incómoda tarea de confirmar la veracidad de los datos. Nos queda voltear la mirada a la vida cotidiana, abrir un buen libro, cambiar de canal, buscar una emisora musical. Mejor aún, volver a alguno de nuestros amados clásicos. Si, todo eso podemos hacer.Peroquiénes podemos hacerlo? Obviamente los que estamos premunidos delos elementes intelectuales y materiales para hacerlo. En el Perú, lo menos.

\section{El valor de la yerdad}

Y -parece mentira tener que decirlo- la verdad es importante. Inherente a] ser humano es su capacidad de descubrir la verdad y sabe nombrarla. Cuando no descubrimos la verdad y no sabemos nombrarla, no hemos alcanzado el grado de lo humano y no se desencadenan los mecanismos transformadores de la realidad. En esta dimensión se juega la humanidad de los seres, porque

A diferencia de los animales, los seres humanos no recibimos una programación genética que nos garantice que vamos a cumplir con nuestra realización 
como especie. Cada uno tiene que debatirse entre el bien y el mal, lo permitido y lo prohibido, y en esa decisión y en esa decisión está el espacio de la ética.'

- En términos individuales la verdad se entiende como la adecuación entre lo que se piensa y se dice o se hace, tiene entonces que ver con las manifestaciones de la interioridad y la coherencia personal. Sin embargo, la verdad tiene además una dimensión social de gran trascendencia. Socialmente la verdad es una responsabilidad (imperativo de sinceridad, honestidad, autenticidad) al ser "una condición fundamental para la convivencia reconciliada y en paz" a la vez que "un derecho que concierne tanto a las personas como a la comunidad, a la sociedad". ${ }^{2}$

La falsedad es intrinsecamente injusta puesto que priva a los sujetos de un entorno de las posibilidad de contar con todos los elementos para dilucidar sus posturas y realizar sus opciones. Cuando ella se institucionaliza, es profundamente injusta porque socava las bases de la relaciones humanas. Desvaloriza las sociedades.

Ubicados en la sociedad peruana es necesario reconocer que el valor verdad ("adecuación entre lo que se piensa y se dice o se hace") es uno de los que mayor fragilidad presenta. En un estudio precedente hallamos, insistentemente, el temor que despierta. Decíamos en esa oportunidad:

Tanto en ámbitos públicos como en las relaciones interpersonales los discursos ponderan el valor de la verdad y, recientemente, de la transparencia. Se insiste, sin embargo, que la exposición de lastdeas debe hacerse en términos mesurados. La voz y las expresionesiseqbchlarnanisuaves y el uso de los eufemismos se prefiere a la exposición clara y contundente de las ideas... quienes optan por la libertad de no hablar a media voz ni perennizar el maquillaje de la realidad son tachados a menudo de "conflictivos". ${ }^{3}$

El ejercicio de la verdad

En el decir de Francisco Moreno, al abordar la cuestión de la verdad no es preciso entrar a especulaciones sofisticadas, cita por eso una fábula en la que

1 Pilar Col.. "Ética y Derechos Humanos" en Verdad y Reconciliación. Lima: CEP, 2002, p. 74

2 Rafael Goto Silva. "La verdad como exigencia para la justicia". En Verdad y Reconciliación. op. cit, p. 84 .

3 Sonia Luz Carrillo. Comunicación, Discurso y Ciudadania. Informe de Investigación. Instituto de Investigaciones Humanisticas de la Facultad de Letras y Ciencias Humanas. UNMSM, 2001, p. 41 
verdad y mentira se confunden y para actualizar el tema en la realidad local e internacional significativamente no encuentra mejor ejemplo que los medios de comunicación:

Esta fábula se comprueba dia a día en los medios de comunicación. Los videos de la corrupción nos han recordado algo muy importante: Los medios de comunicación que suelen apelar a la libertad de expresión, en verdad lo que defienden muchas veces es la libertad de empresa... no están comprometidos en primer lugar con la verdad sino, más precisamente con la noticia, que es algo distinto. Hay una hiperinflación de noticias, por ejemplo, en la reciente guerra de Afganistán, pero al final no sabemos casi nada de lo que pasó sino sólo lo que los dueños de las grandes agencias han querido que llegue hasta nosotros. Ese es el problema para la verdad. ${ }^{4}$

El asunto es que el concepto verdad o veracidad es, teóricamente, el valor más importante en la actividad informativa. Se repite que la sociedad tiene el derecho de ser informada de manera veraz, completa y oportuna. La obligación que tal derecho comporta para el periodismo está presente en todos los códigos de ética de los profesionales de la información y la comunicación. Técnicamente esta obligación ética se expresa en la confrontación de diversas fuentes y la presentación sólo de datos comprobados.

En Etica para periodistas, María Teresa Herrán y Javier Restrepo han realizado un rastreo de la significación que en todo el orbe se le asigna a este valor y señalan: "La lectura comparada de 68 Códigos de Ética permitió comprobar que hay algunas normas éticas que son aceptadas mayoritariamente por los periodistas de los cinco continentes" Registran luego una lista en la que aparece de mayor a menor la aceptación de valores periodísticos. Resultando en primer lugar y con mención en 56 códigos, Ja Veracidad como el primero y es el más universalmente aceptado valor. Posteriormente los autores se interrogan “¿Qué entienden los códigos por veracidad?" Para responderse "El sentido más aceptado es el de la fidelidad a los hechos.... Según esto, la verdad del periodista es su fidelidad en la descripción de los hechos de que es testigo, o sobre los que ha reunido documentación."

Más adelante refieren que El Código de Unesco, redactado después del análisis y comparación de 48 códigos, "anota que en el $71 \%$ de ellos, destaca en

4 Francisco Moreno Rejón. "Verdad y veracidad en la vida cotidiana: el camino de la reconciliación" En Verdad y Reconciliación, op. cir., p. 134. 
primer lugar 'la veracidad, la objetividad y la exactitud'. Este concepto lo expresan en otras palabras los códigos que señalan al periodista que su tarea primordial es la información veridica por su adhesión a la realidad objetiva".

En otro estudio sobre el tema, Rivers y Mathews, reconocen que difundir la verdad significa para los medios masivos dar una imagen completa y exacta del mundo y advierten que "cualquier comportamiento que entre en conflicto con este objetivo se hace sospechoso". Sin embargo también señalan que "muy pronto aprenden los reporteros que la verdad es elusiva y la objetividad puede ser una ilusión". Explican que lejos de las visiones "idealizadas" del periodismo "en el mundo real puede que los reporteros no entiendan la historia que cubren; que vayan a las fuentes erróneas, que hagan preguntas pobres, que formulen juicios erráticos, que enfaticen los puntos equivocados, que falten a la precisión y que se olviden de verificar la información". Y no sólo en el nivel de la producción inmediata sino también se produzcan fallas en otros niveles. Por ejemplo que los editores "tampoco entiendan la historia y la procesen de manera que parezca sencilla y atractiva". De otro lado,también está la lectura que el público hace de la información al percibir el mensaje desde su particular experiencia. ${ }^{6}$

El concepto verdad, en la comunicación masiva, es equiparable al de objetividad. Pero aqui también encontramos que para muchos tiene un carácter casi tan inasible como el de verdad o veracidad. Lo cierto es que la objetividad periodistica resulta un ideal de dificil concreción y para los autores citados ello se debe a que "Todos,jincluyende los reporteres, vìimos en una maraña de presuposiciones y prejuicios". Sin embargo os necesario que los reporteros consideren sus tendencias y traten de mantenerlas fuera de sus productos informativos. ${ }^{7}$

"La objetividad informativa no es posible", sentencian también Villafane, Bustamante y Prado en su libro Fabricar noticias. "Incluso en el caso en el que exista una decidida voluntar por objetivar los acontecimientos que se comunican a la audiencia, el propio proceso de comunicación está organizado de tal manera que hace de esta pretensión algo utópico e imposible". Prefieren por eso colocar el énfasis en establecer los tipos de mediación del que es portador

Maria Teresa Herran y Javier Restrepo Etica para Periodistas Bogotá: Tercer Mundo, editores, 1991, pp. 66-67

6. William Rivers y Cleve Mathews, La Etica en los medios de comunicación. México: Gernika, 1992, p. 70. 
todo producto informativo, entendiendo que las mediaciones son diferenciadas. En primer lugar sitúan la elección que cada medio hace de un conjunto de acontecimientos para convertirlos en noticias de acuerdo a sus particulares criterios, la utilización de unas fuentes en detrimento de otras y luego "el proceso productivo que está impregnado de rutina profesional que constituye una sutil forma de mediación hábilmente disfrazada con criterios de eficacia, productividad y profesionalismo".

Luego de advertir que los periodistas deben estar libres de cualquier obligación o intereses "salvo el derecho del público a conocer la verdad", una Declaración de principios de la Asociación Estadounidense de Editores de Diarios, señala "La verdad es nuestro objetivo último" y luego afiade que la objetividad es la marca del profesional experimentado y una norma de comportamiento hacia la cual todos deben tender. $Y$ termina, no sin humor, con la frase "Honor a quienes lo logran"."

Hay, no obstante, quienes insten, como Luis Alberto Luna Tobar, en que, puesto que la ética señala una línea coherente de pensamiento y actitud afirmada en principios morales universales y termina en constituirse cultura, nada exige tanta presencia ética como la comunicación que relaciona persona y sociedad.

El comunicador vive un insistente litigio entre lo impresionante y lo necesario,... Entre el apego a la verdad y las tentaciones de la mentira. Por eso para el autor, el peligro de estas tensiones estriba en que ellas desequilibran la severidad objetiva y desarman la coherencia necesaria. Como consecuencia, la verdad padece, la objetividad sufre mermas ly la comunicación genera de modo espurio "mentiras, calumnias, insultos..., que con frecuencia alteran a los más serenos, turban el juicio público y violentan el ejercicio de la justicia. ${ }^{10}$

¿Quién decide qué es lo interesante de una noticia?

Hablar de actividad informativa es hablar en primer término de noticia. Existen numerosas definiciones de noticia y en todas ellas resalta como requisi-

7 Rivers y Mathews, Op. cit., p .73.

- J. Villafane. E. Bustamante y E. Prado. Fabricar noticias, Las ruthas productivas en radio y television. Barcelona: Editorial Mitre, 1987, p. 25.

" Rivers y Mathews. Op. cil., p. 367.

"I Luis Alberto Luna Tobar. "Etica y comunicación" en Chasqui No 71. Quito: CIESPAL, 2000. Sección Opinión. Edición Digital www.chasqui.ciespal.org.ec 
to que sean interesantes. Ahí empieza la polémica. Porque quién decide qué es lo interesante? ¿Quién discrimina entre lo interesante y lo importante? Un viejo dicho periodístico repite que "si un perro muerde a un hombre no es noticia, la noticia será que un hombre muerda a un perro". Lo raro, lo inusual, lo entretenido se constituye en la base de la información. La mesa está servida para el sensacionalismo. Esto lleva a Arthur Hays, editor del The New York Times a preguntarse: "Qué es más urgente: informar a mil lectores o entretener a un millón?"."

Hay quienes escapan del esquema de perros y mordidas por eso para José Luis Martínez Albertos (1993):

Noticia es hecho verdadero, inédito o actual, de interés general, que se comunica a un público que pueda considerarse masivo, una vez que ha sido recogido, interpretado y valorado por los sujetos promotores que controlan el medio utilizado para su difusión. ${ }^{12}$

Esta definición es importante porque introduce el tema de la responsabilidad. En primer lugar la preocupación ética al señalar el requisito de la verdad; luego la consideración de las dimensiones del público y el hecho indudable de que es una construcción de los (mediadores' aquellos "productores que controlan el medio". Por eso, más adelante no puede dejar de tocar el tema de la objetividad. Delicado tema porque como señala "Toda noticia supone necesariamente una manipulación: Sin manipulación no hay noticias sino simplemente hechos". Como no podia ser deotras manera, expliea luego que "EI simple hecho de separar unos datos de agecontimian suponeya un cierto grado de manipulación" realizada por un operador semántico dentro de un abanico más o menos amplio de posibilidades combinatorias.

Consciente de las dificultades que presenta la objetividad -la periodista Oriana Fallaci prefiere llamarla buena fe y corrección informativa ${ }^{13}$ - el periodista

"Citado por Mar Fontcuberta. En Estructura de la noticia periodistica. $2^{4}$. ed. Barcelona: ATE, 1981, pp. 10-11.

12 José Luis Martinez Albertos. Curso general de redacción periodistica. Madrid: Paraninfo, 1993, pp. 44-45.

13 En la introducción a su libro Entrevista con la historia, la estupenda periodista italiana sostiene que detesta la palabra objetividad. "Odio o amo cuando estoy frente a mi entrevistado. Prefiero los términos correcto y honesto", señala Oriana Fallaci, quien nuevamente dio muestras de tales convicciones a través de sus crónicas sobre la tragedia del 11 de septiembre en Nueva York, escritas desde Manhattan, donde vive, y publicadas en el diario Corriere della Sera. 
Javier Darío Restrepo escribió hace un lustro un minucioso informe en el que sitúa el tema como componente importante de la crisis de los medios de comunicación. Restrepo ubica el asunto no sólo en el terreno de la ética individual y cita al periodista y corresponsal de guerra polaco Ryszard Kapuscinski: "Habria que entender que una cosa son los hechos y otra es la verdad. Contar en media hora muchos hechos no es necesariamente entregar la verdad de los hechos. Una in formación objetiva, es explicar lo que pasó, la importancia que tiene para la sociedad. De lo contrario, se entrega mucha información que no dice nada. $Y$ cuanta más información se da, el receptor menos entiende"14 Habria que preguntarse también qué tanto quiere 'saber' el receptor.

\section{El contagio entre medios}

Fenómeno caracteristico de la interacción mediática contemporánea es la autoreferencialidad. Es decir, el "contagio" entre los medios. Una vez que un suceso o su representación ha sido instalado en la agenda mediática todos los medios de distinto soporte se verán "obligados" a tocar el tema aunque con distinto grado de despliegue. La noción de actualidad o "realidad" se construye en las salas de redacción de los distintos medios. Tanto que muchos se preguntan si la noticia es aquello que interesa a los lectores o lo que interesa a los periodistas.

Una vez contagiados, enormes cantidades de insumos se usan en función a un puñado de temas que dan origen a notas informativas, posteriormente a entrevistas, reportajes, columnas de opiniỏn, etco La mayor dificultad estriba en que este contagio es percibido por los informadores como un factor de "competencia", la misma que se lleva acabo en medio de enorme tensión que los hace proclives a acciones cada vez más irreflexivas.

"No creo que el público se de cuenta de la brutalidad de la competencia que vivimos hoy en la arena de los periódicos, la radio y la televisión. Hay miedo en todas las salas de redacción de Estados Unidos, aunque nadie lo diga. Hay miedo de que la circulación se hunda o que no crezca. No tienes tiempo para

I4 En abril de 1997, el periodista Javier Dario Restrepo, actual Defensor del Lector de $E l$ Colombiano y quien to fue, durante dos aftos, del diario El Tiempo, publicó en la revista de Andiarios, entidad que agremia a la mayoría de periódicos de Colombia, el artículo. "Objetividad: periodistas, en el filo de la navaja". En ese texto, un tanto profético, asoma ya la nariz chata de la crisis que hoy golpea al mundillo periodistico. 
pensar lo que tienes que hacer porque temes que tu competencia te tome la delantera", señala Rather. ${ }^{15}$

La inmediatez, el miedo a ser adelantado por la competencia, el poco tiempo con que cuenta el comunicador y la rutina en el accionar parecen dejar muy poco espacio para consideraciones que excedan la búsqueda de resultados también inmediatos. La responsabilidad suele ser considerada un lujo inoportuno. Mi experiencia de cerca de dos décadas en la formación de jóvenes comunicadores me indica que si bien en las aulas universitarias tiene o expresan preocupación por valores que trascienden lo inmediato económico, una vez que han ingresado en el tráfago de la vida profesional, muchos no dudan en sumarse a los criterios mediáticos. El argumento de mis ocasionales interlocutores es que deben sobrevivir en un medio altamente competitivo. $\mathrm{Y}$ algunos periodistas profesionales confiesan - off the record- que los aspectos éticos, tan caros en sus años de estudiantes, ahora les aparecen como una carga, incluso contraria al ejercicio profesional.

De otro lado, pareciera que los públicos no desean la verdad y les tiene sin cuidado la falta de objetividad. Personajes mediáticos de probada falta de ética continúan gozando de audiencia. Medios de comunicación, por ejemplo, que actuaron de espaldas a los intereses de la ciudadanía durante la pasada dictadura, obtienen altos porcentajes según las empresas de medición de consumo mediático. $\mathrm{Y}$ todos sabemos que los medios venden porciones de público a sus anunciadores. Entop̧ęs, enda medida que gocen del favor de un segmento importante de público ellos continúan con su rentable práctica.

\section{¿Y qué dice el público?}

Si sabemos que los medios de comunicación no se ciñen exclusivamente a decir lo que pasa sino que construyen la realidad social y la expresan en un discurso hecho de enunciaciones y estrategias que constituyen el discurso de la información del que no es totalmente ajeno el público, es indispensable

${ }^{15}$ En la revista Hora de Cierre, órgano informativo de la Sociedad Interamericana de Prensa. apareció un articulo del periodista Horacio Ruiz Pavón. titulado "En las fauces de la crisis". En él está la mención de Dan Rather, quien hace referencia al miedo para después aconsejar a los directores de los diarios salir de sus confortables oficinas para ir a visitar personalmente a los anunciantes claves. Esta cita la he tomado textualmente de "Crisis y medios de comunicación" articulo de Jaime de La Hoz Sinanca, en: Sala de Prensa, edición $N^{\circ} 44$, junio 2002, año IV, vol. 2 www.saladeprensa.org 
observar el vínculo establecido entre comportamiento de las audiencias y su aceptación de productos comunicacionales, en un juego de negociaciones con muchas de las propiedades de los contextos locales y sociales previamente bosquejados. Porque convertidos en una "segunda piel", los medios de comunicación no sólo han transformado las proyecciones colectivas sino que "las almacenan en los individuos como vivencias". ${ }^{16}$

Por eso la interrogante es ¿qué ocurre en una sociedad que ha vivido una etapa de desinformación tan intensa y promoción sistemática de falsedad $y$, sin embargo, continúa premiando con el consumo a ciertos medios que incurren en el delito? Una respuesta podría venir del ámbito de la moral pública y sus fragilidades en este orden. La suma de circunstancias históricas podrían haber ido tejiendo la percepción de que la verdad es un bien innecesario. Desde una perspectiva histórica podríamos señalar la suma de condiciones sociales y politicas, a través de casi todos los periodos, en las que se percibe la ausencia de responsabilidad individual y social.

Otra explicación provendria del criterio de entretenimiento a cualquier precio que se ha instalado en la actividad informativa concebida como chirriante espectáculo. Las respuestas a algunas encuestas son expresivas: La gente dice encender su televisor para "entretenerse" y luego hallamos que los programas más vistos son los noticieros seguidos de las telenovelas. Baste mirar las cifras de audiencia de programas aparentemente periodísticos que semanalmente promocionan su contenidob con las expresiones de "tespectacular destape", "impactantes imágenes exclusivas", "desgarrador testimonio", "violenta jornada", "sangrientos hechos", etc.

Ante este panorama, al estudiar el discurso informativo, resulta insuficiente analizar su estructuras interna, las acciones que suscita, $o$ las operaciones mentales (procesos cognitivos) que ocurren por el uso del lenguaje. Deviene imprescindible abordarlo como acción social que ocurre en un marco de producción, comprensión, comunicación e interacción, a su vez, partes de estructuras y procesos socio-culturales más amplios. Sólo desde la interdisciplinaridad es posible abordar tan complejo fenómeno de interacciones.

"Hans Dieter Kueler y Gerd Wurzaerg. "El estudio de los medios de comunicación". En Psicologia de los medios de comunicación. Barcelona: Editorial Herder, 1986. p. 174. 